\title{
LA POSICIÓN DE LA JURISPRUDENCIA EN EL SISTEMA DE FUENTES DEL DERECHO COLOMBIANO*
}

\author{
Pedro Javier Barrera Varela ${ }^{1}$
}

\begin{abstract}
RESUMEN
En el presente artículo, se pretende establecer cuál es la posición que tiene la jurisprudencia en el sistema de fuentes del derecho colombiano, haciendo un recorrido histórico desde su adopción en Colombia, auscultando las dificultades metodológicas para la identificación de la ratio decidendi, o razón fundamental para decidir el caso; para finalmente evaluar las disposiciones del Código Administrativo y de lo Procedimiento Administrativo colombiano, donde se le otorga un valor preponderante a la jurisprudencia emitida por el Consejo de Estado como órgano de cierre de la jurisdicción contencioso administrativa, asumiendo una posición crítica frente a la vulneración que estos preceptos pueden causar a los principios de autonomía e independencia judicial y al de separación de poderes, en aquellos eventos en que la Administración se ve obligada a aplicar las sentencias de unificación dictadas por la Sala Plena del Consejo de Estado.
\end{abstract}

\section{PALABRAS CLAVES}

Precedente judicial, ratio decidendi, separación de poderes, precedente vinculante y precedente obligatorio.

\begin{abstract}
In this article, is to establish what position having the jurisprudence in the system of sources of Colombian law, doing a historical tour since its adoption in Colombia, by listening methodological difficulties in identifying the ratio decidendi, or rationale to decide the case; to finally evaluate the provisions of the Administrative Code and the Colombian Administrative Procedure, where it is given an important value to the jurisprudence of the State Council as a body for closing the administrative jurisdiction, assuming a critical position against breaches that these precepts can cause to the principles of autonomy and judicial independence and the separation of powers, in those cases in which the administration is obliged to enforce judgments of unification dictated by the Plenary of the Council of State.
\end{abstract}

\section{KEYWORDS}

Judicial precedent, ratio decidendi, separation of powers, binding precedent binding precedent.

Depositado en agosto 15 de 2014, aprobado en octubre 31 de 2014.

* El presente escrito es producto de la investigación realizada para optar por el título de Magister en Derecho Administrativo en la Universidad Libre titulada "Principialística y derecho administrativo", luego de una reflexión mejorada y ampliada durante los estudios de doctorado en derecho en la Universidad Externado de Colombia.

1 Doctorando en Derecho de la Universidad Externado de Colombia. Magister en Derecho Administrativo de la Universidad Libre de Bogotá, Especialista en Derecho Constitucional de la Universidad Externado de Colombia. Ejecutivo en administración de cartera y procesos especiales de la Seccional de Impuestos de Cartagena. Dirección de Impuestos y Aduanas Nacionales. E.mail: pjabogado26@ gmail.com 


\section{INTRODUCCIÓN}

Independiente de la tradición jurídica a la que se pertenezca, en la actualidad resulta inadmisible entender el precedente judicial, o la jurisprudencia, como un aspecto ajeno al sistema de fuentes del derecho; es decir, que en todo contexto, el precedente va a tener una validez y una utilidad práctica al momento de resolver los casos por parte del intérprete jurídico. Lo que se puede afirmar es que varía en cada escenario jurídico, la capacidad vinculante que tiene el precedente, solo por mencionar un ejemplo, se podría decir que en el sistema norteamericano esta figura, tendría mayor fuerza o capacidad vinculante que en el derecho francés, sin que esto signifique que para los juristas franceses la jurisprudencia y/o sistema de precedentes no sea reconocida dentro de las fuentes del derecho.

Otro aspecto, que, en un principio, tendría alguna validez académica para diferenciar las fuentes que irrigan el derecho, es la tan conocida clasificación entre fuentes primarias y fuentes secundarias, o en algunos casos fuentes principales y criterios auxiliares del derecho. Memorizar esta fórmula y aceptarla como una verdad irrefutable ha hecho que el derecho se estudie de manera fragmentada, y que se asimile como si existiera un derecho de primera (contenido en la ley) y un derecho de segunda, del cual hacen parte la jurisprudencia, la doctrina, los principios generales y la costumbre.

Es así como en este artículo se propone abordar el estudio de las fuentes, no desde la posición tradicional y de acuerdo a la pirámide normativa, sino desde una concepción maleable del derecho, en la cual los diferentes formantes, ya sea Constitución, Ley, Jurisprudencia, principios generales, pueden invocarse para la resolución del caso en concreto, por ello se apela a la tesis de diálogo de fuentes ${ }^{2}$, y se propone una visión del derecho en espiral y no piramidal como otrora se planteó.
Si traemos el debate al caso colombiano y concretamente al derecho administrativo, el actual debate sobre el valor de fuente principal que se le otorga a las sentencias de unificación proferidas por el Consejo de Estado introducido por la Ley 1437 de 2011; no es una postulación del todo novedosa, puesto que el valor normativo de la jurisprudencia en el ordenamiento colombiano lleva consolidándose desde finales del siglo XIX, como se abordara en líneas posteriores.

Desde ya se plantea la situación problemática, de si el reconocimiento de efectos vinculantes de las sentencias de unificación del Consejo de Estado, incluso, para la administración, se constituye un verdadero avance del derecho administrativo, o por el contrario solo es una demostración del exacerbado formalismo, según el cual debió incluirse este precepto en la ley, para que los intérpretes del derecho administrativo asimilaran el contexto constitucional y el peso fundamental que ha adquirido la jurisprudencia en el derecho colombiano; es decir, si la jurisprudencia ha sido reconocida como una fuente del derecho, cuál es la razón para que el derecho administrativo no haya entendido esta dinámica y sea una ley, la que le otorgue esta condición.

Por lo tanto, estas disposiciones de la Ley 1437 de 2011, tienen una doble lectura; de un lado, se predica que se consolida la constitucionalización del derecho administrativo en Colombia, pero por el otro, también se presenta la otra versión, que se trata de un método bastante ortodoxo y formalista por haberse tenido que acudir a la Ley, para comprender una dinámica que se viene consolidando en el ordenamiento colombiano, desde décadas anteriores.

2 Esta teoría en principio tuvo una formulación para el ámbito del derecho internacional privado, pero tiene total aplicabilidad en el derecho público y consiste en buscar una aplicación coherente y coordinada de fuentes del derecho, para solucionar las antinomias o lagunas del derecho. Al respecto Ver. DO AMARAL JÚNIOR. Alberto. El diálogo de las fuentes: fragmentación y coherencia en el derecho internacional contemporáneo. Academia. Revista sobre enseñanza del derecho Año 7. Num. 13. 2009. 


\section{EVOLUCIÓN DE LA JURISPRUDENCIA EN EL ORDENAMIENTO COLOMBIANO}

Cuando se habla de fuentes del derecho, el término que se emplea para referirse a la producción judicial es el de jurisprudencia; sin embargo, teniendo en cuenta que el aspecto que vincula de este formante es el precedente judicial, en adelante se hará mención a este último elemento aunque sin ser sinónimo del vocablo jurisprudencia; ya que por este último se puede entender al conjunto de decisiones que son coherentes y que se dictan sobre un mismo asunto del derecho.

Es decir, que existe una diferencia fundamental entre lo que se entiende por sentencia judicial ${ }^{3}$ y precedente judicial; ya que la sentencia es de obligatorio cumplimiento para las partes, pero el precedente tiene una vocación de permanencia en el tiempo y puede tener efectos vinculantes más allá del caso en concreto. El profesor Pablo Moreno, así lo advierte en los siguientes términos:

"Asumo, y desde ya es evidente, que la relevancia del precedente judicial frente a los casos del presente no se predica de todo el contenido de la sentencia, en cuanto tendencialmente los diferentes sistemas de relevancia del precedente judicial prescriben que se debe adoptar y/o efectivamente en la práctica adoptan una restricción de la relevancia del precedente judicial a una parte específica de la sentencia: la ya anunciada ratio decidendi, también nominada en el contexto estadounidense como holding". ${ }^{4}$

Tomando la definición del diccionario de la Real Academia Española se entiende por precedente, el "Hecho o caso anteriores al que se considera y que son equivalentes a él o le sirven de referencia" ". Por ello, al realizarse una interpretación del término, debe asimilarse que el precedente es un hecho que sirve de fundamento o de base, para hechos posteriores; es así como aplicado a la ciencia jurídica se entiende por precedente judicial la necesaria aplicación de una decisión judicial previa a una posterior, en aquellos casos análogos, o de circunstancias fácticas similares.

Doctrinalmente sobresalen dos tendencias con respecto al valor normativo que debe tener el precedente judicial: La tendencia tradicional y la tendencia reformadora. La primera fundamenta su tesis en un derecho formalista y, por tanto, se erige la ley como fuente principal del derecho, atribuyéndole un valor supletorio a la jurisprudencia, según la cual únicamente se emplea para resolver los problemas hermenéuticos de la ley, ya sea porque esta tiene un significado oscuro, porque contradice otras disposiciones de igual jerarquía o porque no indica una respuesta clara frente al caso en estudio. La segunda tendencia o corriente ve en la jurisprudencia una fuente principal del derecho, y aboga por su fuerza vinculante a través de la creación de líneas de precedentes ${ }^{6}$.

Aunque el precedente tiene gran prevalencia en el derecho anglosajón, es decir, en la tradición del common law, no significa, que se trate de una figura ajena a la tradición francesa, toda vez que fue solo hasta el siglo XIX, con la codificación napoleónica que se cambió un sistema donde tenía preponderancia la jurisprudencia y el derecho de los jueces ${ }^{7}$, por un derecho legislado, donde el juez en palabras de Montesquieu solo era la boca de la ley.

\footnotetext{
3 "Es necesario diferenciar la fuerza obligatoria de las sentencias, con la fuerza normativa del precedente que crean, respecto de decisiones posteriores. Las sentencias de los jueces son obligatorias para las partes, lo que no implica que creen precedentes obligatorios". OSPINA GARZÓN, Andrés Fernando. Los cambios de jurisprudencia en la jurisdicción de lo contencioso administrativo: ¿veleidad o independencia del juez? Contribuciones para el sistema de precedentes jurisprudencial y administrativo. Universidad Externado de Colombia. 2014

4 MORENO CRUZ, Pablo. Una (pequeña) caja de herramientas para el estudio de los sistemas de relevancia (más o menos) vinculante del precedente judicial. (Re)visitando lugares comunes. En Contribuciones para el sistema de precedente jurisprudencial y administrativo. Universidad Externado de Colombia. 2014.

5 Diccionario de la Real Academia de la Lengua Española. Tomado de: http: //rae.es/recursos/diccionarios/drae" 6 Sentencia C-252 de febrero 28 de 2001.

7 Andrés Ospina, expresa en los siguientes términos: "La función del juez no es, ni ha sido, la de ser la boca de la ley, tal como lo afirmó Montesquieu en un momento histórico en el que los jueces luchaban desembozadamente por el poder político y por miedo se creyó en la necesidad de limitar su labor"; y citando a LAFERRIERE, narra el pasaje en el que Luis XIII a través del Edicto del 21 de febrero de 1641 limita el poder de los jueces en Francia. (Op cit. OSPINA GARZÓN)
} 
De igual forma, resulta impreciso decir que el precedente es ajeno a la tradición romanogermánica del derecho, dado que el derecho viviente romano, consistía precisamente en la solución práctica de las controversias jurídicas, es decir, un derecho casuístico, donde no prevalecía una fuente escrita del derecho. Lo que puede concluirse en principio, es que el sistema de precedente judicial es ajeno a un sistema de codificación absoluta como el napoleónico, que fue adoptado por Chile y luego por Colombia, pero que a finales del siglo XIX, ya se vio la necesidad de acudir nuevamente a la jurisprudencia como fuente principal del derecho.

Sin embargo, para llegar al estado actual del peso de la jurisprudencia en el contexto colombiano, resulta de gran significación hacer un recorrido histórico y destacar las diferentes mutaciones de este concepto: doctrina legal, doctrina probable y doctrina constitucional.

Siguiendo al autor colombiano Diego Eduardo López Medina ${ }^{8}$, se entiende que la jurisprudencia tuvo sus orígenes con el movimiento de la Regeneración liderado por Rafael Núñez, por medio del cual se buscaba la unidad de la jurisprudencia nacional para fundar un Estado centralista y eliminar todo vestigio de federalismo.

La figura del precedente judicial se incorporó al ordenamiento jurídico colombiano en el año de 1887 con la tipología "doctrina legal más probable" y consistía en que tres decisiones de la Corte Suprema de Justicia sobre un mismo punto de derecho se tendrán como doctrina más probable y, en consecuencia, los jueces debían aplicarla en casos dudosos.

En 1890 se cambió su denominación y se le llamó doctrina legal. Estaba conformada por la interpretación que la Corte Suprema diera a una misma ley en dos decisiones uniformes, asimismo, como por los pronunciamientos de la corporación sobre situaciones respecto de las cuales existían vacíos en la ley.

Se simplifica entonces el número de decisiones que la constituyen al tiempo que se amplían los eventos en que debe aplicarse, llegando hasta el punto de configurarse como causal de casación la violación de esta institución. Posteriormente, en 1896, se otorga la potestad a los jueces inferiores de apartarse de la que desde entonces se llamo doctrina probable?.

Para abordar el tema del precedente judicial es necesario estudiar la institución de la doctrina probable vigente desde el año 1887, en el ordenamiento jurídico colombiano, toda vez que permite un acercamiento a aquel concepto. Al respecto la Corte Constitucional realizó una afortunada síntesis en una de sus decisiones cuando falló sobre la demanda de constitucionalidad del artículo $4^{\circ}$ de la ley 169 de $1896^{10}$

Según lo expuesto, desde finales del siglo XIX, se ha reconocido un carácter prevalente a las providencias de la Corte Suprema de Justicia ${ }^{11}$ dentro del ordenamiento jurídico, para que los jueces de inferior jerarquía apliquen esta jurisprudencia; empero, en desarrollo del principio de independencia y autonomía judicial se ha discutido si los jueces deben seguir de manera obligatoria este precedente o si, por el contrario, es una decisión discrecional seguir o no el precedente de la Corte Suprema.

Siguiendo el relato del profesor López Medina $^{12}$ se observa que la misma Corte Suprema de Justicia encontró un verdadero obstáculo en la rigidez de la doctrina legal ordenada en las

8 LÓPEZ MEDINA, Diego Eduardo "El derecho de los jueces”, Segunda edición, Legis. Bogotá 2006.

9 ARTÍ́CULO $4^{\circ}$ de la ley 163 de 1896.

10 Sentencia C-836 de 2001.

11 Con esto no se quiere decir que solo tengan ese carácter importante las decisiones de esa Corporación, pues es sabido que con la actual estructura jurisdiccional la Corte constitucional y el Consejo de Estado también lo han adquirido hasta el punto de existir confrontaciones entre ellas en defensa de su prevalencia.

12 Ibíd pp. 21-24. 
Leyes 61 de $1886^{13}, 153$ de $1887^{14}$ y 105 de $1890^{15}$, por lo cual se expusieron dos argumentos centrales:

- Autoprecedente (precedente horizontal): La doctrina legal congelaba prematuramente la jurisprudencia.

- Precedente vertical: obligaba a los jueces inferiores a buscar la regla general explícitamente anunciada por la sentencia y no la ratio decidendi de la misma, es decir, los argumentos que permitían que un determinado caso se hubiera decidido de determinada forma.

Estas críticas emanadas del supremo órgano de justicia rápidamente tuvieron eco en el Congreso de la República y conllevó a una reforma de la institución, modificando el concepto "doctrina legal" por la tipología "doctrina probable", mediante la expedición de la Ley 169 de 1896 que en lo relacionado a esta institución introdujo dos reformas:

- El artículo $2^{\circ}$ de esta ley, redefinió la causal primera de casación en el sentido de que únicamente configura la causal la interpretación errónea de la ley, o su indebida aplicación en el pleito.

- El artículo $4^{\circ}$ modificó el artículo 10 de la Ley 153 de 1887 y dispuso lo siguiente: "Tres decisiones uniformes dadas por la Corte Suprema de Justicia como Tribunal de Casación sobre un mismo punto de derecho constituyen doctrina probable, y los jueces podrán aplicarla en casos análogos, lo cual no obsta para que la Corte varíe la doctrina en casos de que juzgue erróneas las decisiones anteriores" 16

De acuerdo con el análisis del autor López Medina esta disposición rápidamente fue asumida por la civilística nacional a través de la "escuela de la jurisprudencia libre"; es decir, en el cual los jueces y tribunales tienen absoluta discrecionalidad para aplicar la jurisprudencia, toda vez que no es asumida como fuente formal del derecho. Se observa que se quiso implantar un sistema de tarifa jurisprudencial, como si hubiese una fórmula exacta para que las sentencias de la Corte Suprema tuvieran la vocación de erigirse en jurisprudencia.

Con la entrada en vigencia de la Constitución de 1991 se abrió paso a la jurisdicción constitucional con la creación de la Corte Constitucional; por lo cual, a partir de 1992 comienza un nuevo período en torno al debate sobre el papel que desempeña la jurisprudencia en el ordenamiento jurídico colombiano. El autor en cita, identifica tres períodos a saber: 1992-1995, 1995-2001, 2002-2006.

Durante el primer período el Ejecutivo propugnó por un sistema fuerte de precedente y lideró la propuesta que conllevó a la expedición del Decreto 2067 de 1991, que con la jurisprudencia emanada de la Corte Constitucional se le denominó “doctrina constitucional”, según la cual la jurisprudencia, además de tener un carácter pedagógico, también tiene un carácter normativo-general. No obstante, al interior de la Corte se libraron disputas entre el ala tradicionalista y el ala reformista de esta Corporación, imponiéndose la primera, y con ello el criterio de auxiliaridad de la jurisprudencia, toda vez que en la Sentencia C-013 de 1993 se declararon inexequible apartes de los artículos 21 y 23 del Decreto 2067 de 1991, con lo cual el efecto de las sentencias proferidas por esta Corporación se reducían únicamente a las partes en litigio ${ }^{17}$. Fue así como no hubo un avance significativo en relación con la fuerza del precedente constitucional, ya que fue mermada la labor del Ejecutivo por la misma Corte Constitucional.

13 Ley 61 de 1886 "Provisional sobre organización y atribuciones del Poder Judicial y el Ministerio Público y algunos procedimientos especiales.

14 Ley 153 de agosto 15 de 1887 "Por la cual se adiciona y reforma los códigos nacionales, la ley 61 de 1886 y la 57 de 1887

15 Ley 105 de 24 de noviembre de 1890 "Sobre reformas a los procedimientos judiciales".

16 Ibíd. p. 25.

17 Ibíd. p. 32 
Un logro que debe destacarse en este primer período es la interpretación sistemática que el Tribunal Constitucional realiza del precepto contenido en el inciso $1^{\circ}$ artículo 230 de la Constitución Política, aclarando que cuando la disposición se refiere a "ley" debe entenderse el contexto del ordenamiento jurídico ${ }^{18}$, ampliando el marco a las otras fuentes como la jurisprudencia.

Durante el período 1995-2000, la Corte reconstruye una doctrina fuerte de precedentes mediante la utilización expansiva del concepto de "doctrina constitucional" y mediante la aplicación del principio a la igualdad ${ }^{19}$. Esta tesis finalmente es asumida por la Corte de manera unánime, y en la sentencia C-037 de 1996 al realizar el examen de constitucionalidad de la Ley Estatutaria de la Administración de Justicia declara inexequible el artículo 45 que establecía reglas sobre retroactividad de los fallos de constitucionalidad. Igualmente, declara inexequible apartes del artículo 48 que establecía: "solo la interpretación que por vía de autoridad hace el Congreso de la República tiene carácter obligatorio general", ${ }^{20}$ concluyendo que sólo la Corte puede definir el alcance de sus propios fallos. ${ }^{21}$ Esta última es una clara manifestación del método que utilizaba la escuela del positivismo formalista, la interpretación por autoridad. Al declararse inexequible esta disposición se da un paso más hacia el modelo axiológico.

Posteriormente la Corte continúa defendiendo su tesis de obligatoriedad del precedente y lo ratifica en sentencia SU-047/99.

En el tercer período, se destaca la sentencia C-836 de $2001^{22}$ mediante la cual reinterpreta la noción de "doctrina probable". Al revisar la constitucionalidad del artículo $4^{\circ}$ de la ley 169 de 1896 la Corte armoniza el sentido de esta norma con el contexto actual para decir que este artículo no es exclusivo de la Corte Suprema de Justicia sino que aplica para todas las Cortes de cierre que no existían en el contexto histórico en que fue expedida la norma. La Corte Constitucional armoniza los términos "problable" y "erróneas" contenidos en el artículo $4^{\circ}$ concluyendo que la doctrina probable no debe entenderse como una facultad discrecional y en consecuencia no se puede desconocer caprichosamente la jurisprudencia so pretexto del principio de autonomía judicial, porque estaría omitiendo el cumplimiento a un deber constitucional y no se garantizaría la aplicación del principio de igualdad; de otra parte, en aplicación del artículo $4^{\circ}$ se permitía a la Corte Suprema de Justicia que variara su jurisprudencia cuando encontrare erróneas las decisiones anteriores, no obstante en interpretación de la Corte el "error en sentencias anteriores" no implica una patente de corso para abstenerse del deber de aplicar el precedente, para juzgar errónea una decisión anterior es necesario una motivación suficiente que permita un cambio en la jurisprudencia de la Corporación ${ }^{23}$.

Este planteamiento es bastante interesante, porque determina la concepción actual del precedente judicial, es decir, que desempeña un papel de fuente principal dentro del ordenamiento, pero que a su vez, y luego de ponderar el principio de autonomía e independencia judicial con el de igualdad en la aplicación de las decisiones judiciales, inscribe el modelo colombiano en un sistema de precedente vinculante pero no obligatorio, porque existe la posibilidad en función al principio de autonomía de aparatarse, razonada y motivadamente, del precedente jurisprudencial.

Luego de haber mencionado el camino que ha recorrido la jurisprudencia como fuente del derecho en Colombia, este trabajo se centrará en abordar lo relacionado con el precedente judi-

\footnotetext{
18 C-486 de 1993.

19 Ibídem.

20 Ibíd. p. 53.

21 C-037 de 1996.

22 Corte Constitucional de Colombia. Sentencia de Constitucionalidad C-836 de 2001.

23 Ibíd. pp.75-83.
} 
cial, haciendo énfasis en una posible metodología de fácil identificación por parte del intérprete jurídico.

\section{EL PROBLEMA DE IDENTIFICACIÓN DE LA RATIO DECIDENDI}

En la sentencia T-292 de $2006^{24}$, la corte estudió una acción de tutela que se relacionaba con una suspensión de pensión a una viuda de un trabajador de la flota mercante por el hecho de haber contraído nuevas nupcias. En esta decisión la Corporación realiza un importante estudio sobre el carácter vinculante de la parte motiva de las sentencias de la Corte Constitucional y el fundamento de su carácter vinculante, así como una diferenciación entre los conceptos de ratio decidendi y precedente.

En primer lugar, aclara la Corte que es necesario armonizar, los artículos 4, 241 y el 243 de la Carta, con los artículos 230 y 228 de la Constitución, para concluir que la jurisprudencia constitucional no solo sirve como criterio auxiliar de interpretación.

En relación con el carácter vinculante de la jurisprudencia constitucional en dicha oportunidad se señaló que:

(...) frente a la diferencia entre la jurisprudencia constitucional y la de las demás Corporaciones, la divergencia ostensible entre unas y otras es que "la jurisprudencia constitucional tiene fuerza de cosa juzgada constitucional -art. 243 $\mathrm{CP}-$, de suerte que obliga hacia el futuro para efectos de la expedición o su aplicación ulterior" -material y formalmente -, mientras que las demás providencias "sólo tienen un carácter de criterio auxiliar -art. $230 \mathrm{CP}$-, para los futuros casos similares". ${ }^{25}$
Sobre este aspecto se precisa, entonces, que la jurisprudencia emanada del organismo de cierre de la jurisdicción constitucional, tiene fuerza vinculante dentro del ordenamiento jurídico, lo que le otorgaría una jerarquía especial en el sistema de fuentes, que se postula en el artículo constitucional 230. Así las cosas, además de la Constitución y la Ley, las sentencias que pronuncia la Corte Constitucional y hacen tránsito a cosa juzgada constitucional ${ }^{26}$ tendrían un predominio sobre las demás fuentes del ordenamiento, siendo incluso de aplicación directa o principal. Se concluye entonces, que esta jurisprudencia tendría el carácter de fuente principal del derecho, pero resulta discutible, ya que no solo la Corte Constitucional funge como organismo de cierre sino también la Corte Suprema de Justicia y el Consejo de Estado, en sus respectivas jurisdicciones.

Este trabajo se aparta de esta interpretación de la Corte Constitucional, ya que le otorga el carácter vinculante al precedente, aduciendo exclusivamente un criterio jerárquico y no material; toda vez que, como ya se indicó, también la producción de las otras altas cortes tiene la vocación de erigirse en precedente vinculante y no solo como criterio auxiliar; incluso, las decisiones de tribunales y jueces podrían tener la vocación de servir como precedente judicial.

En esta misma providencia, y haciendo una recopilación sobre la línea jurisprudencial del precedente, la Corte precisa el alcance de los siguientes conceptos:

Cosa juzgada explícita: Goza de cosa juzgada explícita la parte resolutiva de las sentencias, por expresa disposición del artículo 243 de la Constitución.

Cosa juzgada implícita o ratio iuris: Goza de cosa juzgada implícita los conceptos de la parte

24 Corte Constitucional. Sentencia de Tutela T-292 de 2006. expediente T-1222275.

25 Ibíd.

26 El artículo 230 de la constitución que le otorga un carácter de criterio auxiliar a la jurisprudencia debe armonizarse con el artículo 243 superior, donde se le asigna una condición de cosa juzgada constitucional a las decisiones de la Corte Constitucional cuando conoce en sede de acción de constitucionalidad. 
motiva que guarden una unidad de sentido con el dispositivo de la sentencia, de tal forma que no se pueda entender éste sin la alusión a aquéllos. Doctrina constitucional integradora: Aquella que ante una laguna suple un vacío jurídico en el ordenamiento, es obligatoria porque responde a una aplicación directa de la Constitución, ante la ausencia de disposición legal.

Doctrina constitucional interpretativa: No es vinculante para las autoridades como fuente de derecho, salvo las decisiones que hacen tránsito a la cosa juzgada. Es criterio auxiliar para los jueces según el 230 constitucional ${ }^{27}$.

Más adelante, la Corte realiza una precisión conceptual frente a los términos: decisum, ratio decidendi y obiter dicta. En relación con el primero, explicó la sentencia, que debía reconocerse como tal, la resolución concreta del caso. No obliga sino, generalmente, a las partes en el litigio, con fuerza de cosa juzgada, pero en las sentencias de constitucionalidad tiene efectos erga omnes.

Por su parte, la ratio decidendi, (razón determinante) precisó que ella debía considerarse como "la formulación general (...) del principio, regla o razón general que constituyen la base de la decisión judicial especifica. [o] si se quiere, el fundamento normativo directo de la parte resolutiva". Al ser "base necesaria de la decisión", 28 resulta ser de obligatoria aplicación por los jueces, en otras situaciones similares. La ratio decidendi además, define "la correcta interpretación y adecuada aplicación de una norma".

Obiter dictum o dicta, (lo que se dice de paso) “...toda aquella reflexión adelantada por el juez al motivar su fallo, pero que no es necesaria a la decisión; [esto es, las] opiniones más o menos incidentales en la argumentación del funcionario". ${ }^{29} \mathrm{El}$ obiter dicta, acorde con esta providencia, tiene un carácter no vinculante y sí eminentemente persuasivo.

Finalmente, el otro gran aporte de esta pieza jurisprudencial es lo relacionado con unos méto- dos para identificar la ratio decidendi, y que se indican a continuación:

Para sentencias de control abstracto, se deben identificar los siguientes aspectos:

(i) la norma objeto de decisión de la Corte,

ii) el referente constitucional que sirvió de base a la decisión y

iii) el criterio determinante de la decisión

\section{Método de identificación de la ratio decidendi:}

i) La sola ratio constituye en sí misma una regla con un grado de especificidad suficientemente claro, que permite resolver efectivamente si la norma juzgada se ajusta o no a la Constitución. Lo que resulte ajeno a esa identificación inmediata, no debe ser considerado como ratio del fallo;

ii) la ratio es asimilable al contenido de regla que implica, en símisma, una autorización, una prohibición o una orden derivada de la Constitución;

iii) la ratio generalmente responde al problema jurídico que se plantea en el caso, y se enuncia como una regla jurisprudencial que fija el sentido de la norma constitucional, en la cual se basó la Corte para abordar dicho problema jurídico. ${ }^{30}$

Luego de identificar estos elementos se pueden responder las siguientes preguntas: 1) ¿por qué la Corte declaró inexequible una norma de determinado contenido?,2) ¿por qué concluyó que dicha norma violaba cierto precepto constitucional?, 3) ¿por qué fue necesario condicionar la exequibilidad de una norma, en el evento de que la sentencia haya sido un fallo condicionado ${ }^{31}$.

Del anterior análisis se concluye que en Colombia existe una obligatoriedad relativa del precedente, toda vez, que aunque son vinculantes, no obligan de manera absoluta porque es posible modificar la decisión anterior siempre y cuando

27 Ibíd. T-292 de 2006.

28 Ibíd.

29 Ibídem.

30 Ibíd.

31 Ibíd. 
se respeten unas cargas argumentativas que en caso de no cumplirse, la decisión de no observar el precedente sería arbitraria. Esta obligatoriedad relativa, también se conoce como el precedente vinculante, porque existe esa posibilidad de apartarse. La Corte ha puesto de presente las siguientes cargas:

Carga de transparencia: "Los jueces deben mostrar transparentemente que existe una doctrina establecida que va a ser cambiada en su nuevo fallo. Esta carga exige, además, que se citen las sentencias hito en las que se anuncia dicha doctrina y que se haga una reconstrucción caritativa y poderosa de las razones que llevaron a su adopción". ${ }^{32}$

Carga de argumentación: se deberá justificar de manera adecuada y suficiente el motivo que conlleva apartarse del precedente. Las justificaciones suficientes y adecuadas se concretan usualmente en:

... (i) cambios legislativos, (ii) cambios sociales, económicos y políticos que generan obsolescencia o injusticia en la aplicación de la doctrina vigente o, finalmente (iii) las altas Cortes, pueden considerar que la jurisprudencia es errónea, por ser contraria a los valores, objetivos, principios y derechos en los que se fundamenta el ordenamiento jurídico ${ }^{33}$.

Aunque no fue fijado en esta sentencia otro aspecto determinante para medir la fuerza vinculante del precedente judicial es el principio ceteris paribus, que explica:

(...) cuanto más abstracta es la regla derivada del caso A, mayor es el número de casos que esta regla alcanza, pero menor es su grado vinculante, pues se torna más probable el surgimiento de una circunstancia no considerada inicialmente, la cual puede justificar la formulación de una regla excepcional para el nuevo caso. Del mismo modo, cuanto más concreta es la regla derivada de un caso A, menor es el número de casos que ella podrá abarcar, pero más elevada será su fuerza para decidir un caso B. ${ }^{34}$

La Corte Constitucional continúa con su línea jurisprudencial y en sentencias como la SU120/2003 esta Corporación le reprocha a la Corte Suprema de Justicia el hecho de que no haya cumplido adecuadamente con las cargas argumentativas al momento de variar su jurisprudencia que estaba vigente hasta 1999. Culminando este período la Corte ha sido enfática al afirmar que se deben respetar los principios del precedente judicial. A manera de ejemplo se citan las sentencias C-120/2003, T-1130/2003 y $\mathrm{T}-422 / 2005$, en las cuales reafirma los postulados definidos en la sentencia C-836 de $2001^{35}$.

Igualmente, nuevas tesis como las de causales genéricas y específicas de procedibilidad contra las sentencias judiciales ${ }^{36}$, que consiste en la posibilidad de accionar por vía de tutela aquellos procesos donde ya se produjo sentencia judicial y que la misma se encuentra en firme, por vulneración de los derechos fundamentales; de igual forma, la del vicio de sustitución ${ }^{37}$, según el cual puede realizarse un control de constitucionalidad sobre los actos legislativos que reforman la Constitución, cuando lo que se pretende es sustituir la carta superior por otra, siendo evidente un exceso en la competencia de reforma que tiene dicho organismo; sin duda

\footnotetext{
32 Ibíd. LÓPEZ MEDINA, Diego p.92.

33 Ibíd. p. 93

34 DA ROSA DE BUSTAMANTE, Thomas. La interpretación y la fuerza gravitacional de los precedentes judiciales: fragmentos de una teoría del precedente judicial. Contribuciones para el sistema de precedentes jurisprudencial y administrativo. Universidad Externado de Colombia. 2014. 35 Ibíd. pp.- 94-95.

36 Sobre esta materia el profesor Manuel Quinche ha realizado un estudio detallado de la evolución de esta figura en Colombia. Ver QUINCHE RAMÍREZ, Manuel Fernando "VÍAS DE HECHO"; Bogotá, Ediciones Doctrina y Ley. 2005.

37 Sobre el juicio de sustitución la Corte Constitucional ha proferido, entre otras, las sentencias. C 1040 de 2005, C 588 de 2009 , C 141 de 2010, C 249 de 2012, y C 1056 de 2012, pronunciamientos en los cuales se ha declarado la inexequibilidad de actos legislativos, admitiendo que en dichas ocasiones el Congreso de la República excedió sus competencias de reforma constitucional., al haber variado elementos, principios o valores que son de la esencia de la Constitución Política de 1991.
} 
alguna son motivo que lleva a concluir el carácter prevalente y de fuente principal que goza la jurisprudencia de la Corte Constitucional en el sistema de fuentes en Colombia.

De lo anterior, se concluye que el precedente judicial es una herramienta útil para la justificación de las decisiones judiciales, es decir, que sirve como regla de decisión en un caso en concreto; sin embargo, no puede desconocerse que en ocasiones el intérprete realiza un ejercicio diferente, es decir, no emplea el precedente como camino o motivación para llegar a una solución del caso, sino que primero adopta una decisión, según su intuición o criterio, y luego busca el método que mejor le parezca para motivar y darle sustancia a esa decisión que está en sus manos.

Uno de los fundadores del movimiento de los Critical Legal Studies, Duncan Kennedy, describe el proceso de la argumentación judicial y concluye que el juez siempre adapta unos argumentos de acuerdo a la sentencia a la que quiere llegar, lo cual resulta perfectamente válido porque el ordenamiento jurídico le ofrece alternativas a los jueces, así se trate de decisiones totalmente opuestas; por lo tanto, el intérprete cuenta con un amplio margen de libertad para tomar sus decisiones, pero se restringe a sí mismo, por los límites que le impone el derecho ${ }^{38}$

Esta es una realidad que no puede desconocer el derecho, por ello el precedente judicial puede ser una manera de reducir este amplio margen de discrecionalidad judicial, porque se privilegia la igualdad en aquellos casos de circunstancias fácticas semejantes.

\section{EL PAPEL DE LA JURISPRUDENCIA EN LA LEY 1437 DE 2011}

Si se acude a la primera postura planteada en la introducción de este trabajo, se afirma entonces, que la jurisdicción administrativa ha logrado un avance con la expedición de la Ley 1437 de 2011, ya que se realiza una actualización de los contenidos procesales del derecho administrativo a la nueva perspectiva constitucional del ordenamiento colombiano, y que se supera la tradición legalista del anterior código de 1984, que fue expedido en vigencia de la Constitución de 1886.

Siguiendo esta posición, resulta afortunado, que en tres disposiciones de este nuevo código se le otorgue a la jurisprudencia un papel fundamental dentro del sistema de fuentes en el derecho colombiano, máxime cuando en la jurisdicción contencioso administrativa existen fuertes rezagos de ese positivismo decimonónico, tal es el caso del principio de justicia rogada, el cual resulta descontextualizado y ajeno a los nuevos postulados constitucionales.

La Ley 1437 de 2011, tiene la bondad de haber recogido la realidad constitucional del momento, es decir, que se sale un poco de ese positivismo normativista, en el cual existe un sistema escalonado de fuentes, y la Ley funge como fuente principal sin que pueda otorgársele ese carácter a otra fuente, para pasar a un modelo positivista con apertura hacia los hechos ${ }^{39}$; y con base en esa nueva realidad constitucional que está conformada no solo por los preceptos constitucionales, sino por las normas que integran el bloque de constitucionalidad, las sentencias de la Corte Constitucional, de las Altas Cortes, e incluso la jurisprudencia de la Corte Interamericana de Derechos Humanos, traída al ordenamiento colombiano a través del concepto de Juicio de Convencionalidad; se establece que el sistema de fuentes es dinámico y la Ley ya no es la única fuente principal o de obligatorio cumplimiento por parte de los intérpretes del derecho.

El derecho administrativo antes de la expedición de la Ley 1437 de 2011, se encontraba inconexo con esta nueva realidad constitucional, y por lo tanto se veía un rezago, incluso en la jurisprudencia que producía el mismo Consejo

38 KENNEDY, Duncan. Libertad y Restricción en la decisión judicial. Siglo del Hombre Editores. 1999.

39 Sobre los modelos del derecho que se encuentran actualmente vigentes. Ver FARALLI, Carla. La Filosofía del derecho contemporánea. Trad. Santiago Perea Latorre. Universidad Externado de Colombia, Bogotá. 2007. 
de Estado, dado que estaba anclado a los postulados del Decreto 01 de 1984. Sin duda alguna, esta reforma que impregnó en varios principios y postulados de los procedimientos de la administración y también de la jurisdicción contenciosa administrativa, también debía realizarse en relación con el nuevo estatus de la jurisprudencia en el ordenamiento colombiano.

En primer lugar, en el artículo 10 de la citada Ley, se fijó el deber de aplicar de manera uniforme las normas y la jurisprudencia, y lo interesante de esta norma es que está dirigida no solo al funcionario judicial, sino a toda la Administración Pública; es decir, que todo aquel que interprete el derecho sin necesidad de que sea juez deberá aplicar de manera uniforme el derecho de conformidad con las sentencias de unificación que produce el Consejo de Estado.

Este aspecto es de trascendental importancia, porque se rompe el viejo paradigma de que el juez solo se limita a la aplicación de la Constitución, la Ley y el Reglamento; ampliando el sistema de fuentes para el funcionario público y vinculándolo a la jurisprudencia. Ahora bien, los efectos que tendría sería de igual forma "vinculante" más no "obligatorio", dado que aunque el funcionario público carece del principio de independencia y autonomía judicial, si resulta aplicable el principio de separación de poderes, y bajo tal postulado no se puede entender una imposición absoluta de la actividad de los jueces sobre la administración ${ }^{40}$, por lo mismo se considera que en igual condición que el juez, la administración puede apartarse del precedente judicial siempre y cuando cumpla con las cargas argumentativas: la carga de transparencia y la carga de argumentación.

En el artículo 102, el nuevo Código Contencioso Administrativo hace explícito el carácter prevalente de la jurisprudencia en el ordenamiento jurídico colombiano, concretamente en lo que atañe a las sentencias de unificación dictadas por el Consejo de Estado; expresando de manera imperativa “deberán”, implica que las autoridades tienen la obligación de extender los efectos de una sentencia de unificación jurisprudencial, para lo cual establece un procedimiento a través del cual un interesado podrá peticionar para que se dé cumplimiento a esta disposición.

Finalmente, en el artículo 256 donde se establece el recurso de unificación de jurisprudencia, y donde se busca expulsar interpretaciones que no se ajusten a las del organismo de cierre. Este medio de impugnación procede contra sentencias dictadas en primera y segunda instancia, la causal es apartarse de la jurisprudencia del Consejo de Estado, si la administración no quiere extender la jurisprudencia se acude al Consejo de Estado vía ese recurso. Solo frente a las sentencias de unificación del Consejo de Estado.

Sobre estas disposiciones, se observa que se da una connotación de obligatoriedad, lo cual difiere del carácter vinculante que tiene el precedente judicial en Colombia, salvo que se trate de aquellos casos donde opera la cosa juzgada constitucional, que la sentencia tiene efectos obligatorios al excluir una norma del ordenamiento, puesto que no se puede volver a reproducir dicho precepto.

Como ya se explicó, el hecho de que el precedente sea vinculante y no obligatorio, implica que el intérprete se puede apartar del mismo siempre y cuando cumpla con las cargas argumentativas, pero en el artículo 102 el legislador no dejó mayor posibilidad, salvo que se pueda entender según el numeral $3^{\circ}$ una especie de apartamiento, al negarse la petición de extensión de jurisprudencia, exponiendo clara y razonadamente los argumentos por los cuales no se debe interpretar la norma de acuerdo con la sentencia de unificación; no obstante, esta decisión será confirmada o revocada por el mismo Consejo de Estado de acuerdo al procedimiento previsto en el artículo 269 del CPACA.

40 Héctor Santaella propone con base en los pronunciamientos de la Corte Constitucional la tesis de sujeción intermedia de la Administración a la jurisprudencia, es decir, la posibilidad de un apartamiento administrativo del precedente. SANTAELLA QUINTERO, Héctor. La sujeción de la administración a los precedentes jurisprudenciales. Contribuciones para el sistema de precedentes jurisprudencial y administrativo. Universidad Externado de Colombia. 2014. 
Se considera que estos preceptos pueden contravenir de una parte el principio de autonomía e independencia judicial, porque somete la actividad del juez a una interpretación única contenida en las sentencias de unificación del Consejo de Estado, incluso se llega a petrificar el derecho; y por otra parte, el principio de separación de poderes, porque al someter a todas las autoridades se incluyen no solo los jueces, sino las autoridades administrativas, de tal suerte que estaría imponiendo vía legal una interpretación única e inequívoca por parte del Consejo de Estado.

En igual medida, esta disposición estaría haciendo carrera para una especie de interpretación auténtica, figura ya superada, propia de un formalismo decimonónico, según la cual el Congreso o cuerpo legislativo era el único autorizado para interpretar con autoridad el espíritu de la ley.

Luego, se ha aprobado una disposición legal, según la cual existe un intérprete autorizado de las sentencias de unificación que es el Consejo de Estado, y que puede someter a su interpretación no solo a los jueces de la jurisdicción contenciosa administrativa, sino a todas las autoridades públicas; como se podría entonces, dirimir un conflicto entre las sentencias de la Corte Constitucional y las de unificación que emite el Consejo de Estado.

Ahora bien, en Colombia persiste la cultura de producir sentencias engorrosas, demasiado extensas, y el intérprete jurídico, o mal empleado término de "operador jurídico" debe plasmar su erudición en la sentencia, empleando términos complejos, incluso descontextualizados, lo que dificulta entonces la labor de identificación de la ratio decidendi, es decir, que fácilmente se pueden extraer diversas reglas de aplicación a casos posteriores, sería entonces ir en contra del derecho, o se podría, igualmente, iniciar un proceso de prevaricato por haber interpretado de manera diferente un caso, o una disposición a como lo hizo el Consejo de Estado.

De acuerdo con los artículos 102 y 256 del CPA$\mathrm{CA}$, es que se puede entender una segunda postura de retroceso y no de avance del derecho administrativo con ocasión de la expedición de la
Ley 1437 de 2011; ya que se trataría entonces de buscar anclar el derecho a una sola visión, haciendo apología a una petrificación del derecho propiciada por el Consejo de Estado.

Finalmente se considera que no había necesidad de elaborar procedimientos tan complejos y rígidos para privilegiar la posición fundamental que cumple la jurisprudencia en el ordenamiento colombiano, puesto que se ha saturado el sistema con nuevos procesos ante el máximo tribunal de lo contencioso administrativo, cuando sencillamente la jurisprudencia ya cumple un rol determinante. Ahora bien, si lo que se hizo fue equiparar la jurisprudencia del Consejo de Estado a la de la Corte Constitucional, buscando tener la misma fuerza o carácter vinculante, el camino no era a través de la ley, sino por medio de las mismas líneas jurisprudenciales del Consejo de Estado; es decir, que el mejor mecanismo, era fortalecer y fijar las líneas claras de precedentes en las distintas secciones del Consejo de Estado, y reelaborar un método más sencillo y más asequible para producir sus sentencias, para que dichas providencias vayan dirigidas no a un selecto grupo de expertos, sino a todo el conglomerado de ciudadanos colombianos.

\section{CONCLUSIÓN}

Aunque se ha dado un significativo avance, en el reconocimiento y posición de la jurisprudencia en el ordenamiento colombiano, y ahora en materia de lo contencioso administrativo, principalmente con las sentencias de unificación dictadas por el Consejo de Estado, que recepciona elementos propios de la tradición anglosajona del derecho, lo que implicaría una actualización del derecho y continuo avance, gracias a la posición dinámica de la jurisprudencia en el ordenamiento, debe advertirse que esta pretensión podría traer el efecto contrario al tratar de petrificarse el derecho por vía jurisprudencial, toda vez que los jueces y demás intérpretes del derecho se verían totalmente atados a posiciones mayoritarias del Consejo de Estado, lo que en muchas ocasiones iría en contra del principio democrático, según el cual las decisiones políticas se deben tomar por una mayoría parlamentaria y no judicial. 
Es así que resulta relevante el estudio de la jurisprudencia, no como un deber de repetición absoluta de las sentencias de las altas cortes, sino como una posibilidad de actualizar el derecho con las nuevas dinámicas y realidades constitucionales, diferenciando entre lo que es vinculante de la sentencia, y lo que simplemente es un obiter dicta, y se comprende que el juez puede apartarse del precedente siempre y cuando cumpla con las cargas argumentativas que para el efecto se le exigen.
Por lo tanto, si bien el papel de la jurisprudencia en el sistema de fuentes saca al jurista de este sistema cerrado, escalonado de normas, el cual es bastante rígido, para situarlo en un ordenamiento más dúctil, con un marcado predominio de los principios y derechos constitucionales, se puede caer en el extremo de petrificar el ordenamiento de las altas cortes, con figuras como la extensión de los efectos de las sentencias de unificación del Consejo de Estado, adoptada en la Ley 1437 de 2011.

\section{REFERENCIAS}

BARRERA VARELA, Pedro Javier. El discurso de la principialística en el derecho administrativo colombiano. 2013. Libro en proceso de publicación.

Diccionario de la Real Academia de la Lengua Española. Tomado de: http: //rae.es/recursos/diccionarios/drae"

DA ROSA DE BUSTAMANTE, Thomas. La interpretación y la fuerza gravitacional de los precedentes judiciales: fragmentos de una teoría del precedente judicial. Contribuciones para el sistema de precedentes jurisprudencial y administrativo. Universidad Externado de Colombia. 2014.

DO AMARAL JÚNIOR. Alberto. El diálogo de las fuentes: fragmentación y coherencia en el derecho internacional contemporáneo. Academia. Revista sobre enseñanza del derecho. Año 7. Núm. 13. 2009.

FARALLI, Carla. La Filosofía del derecho contemporáneo. Trad. Santiago Perea Latorre. Universidad Externado de Colombia, Bogotá. 2007.

KENNEDY, Duncan. Libertad y Restricción en la decisión judicial. Siglo del Hombre Editores. 1999.

MORENO CRUZ, Pablo. Una (pequeña) caja de herramientas para el estudio de los sistemas de relevancia (más o menos) vinculante del precedente judicial. (Re) visitando lugares comunes. En Contribuciones para el sistema de precedente jurisprudencial y administrativo. Universidad Externado de Colombia. 2014.

LÓPEZ MEDINA, Diego Eduardo "El derecho de los jueces”, Segunda edición, Legis. Bogotá 2006.

OSPINA GARZÓN, Andrés Fernando. Los cambios de jurisprudencia en la jurisdicción de lo contencioso administrativo: ¿veleidad o independencia del juez? Contribuciones para el sistema de precedentes jurisprudencial y administrativo. Universidad Externado de Colombia. 2014

QUINCHE RAMÍREZ, Manuel Fernando “VÍAS DE HECHO”; Bogotá, Ediciones Doctrina y Ley. 2005.

SANTAELLA QUINTERO, Héctor. La sujeción de la administración a los precedentes jurisprudenciales. Contribuciones para el sistema de precedentes jurisprudencial y administrativo. Universidad Externado de Colombia. 2014.

\section{JURISPRUDENCIA}

C-037 de 1996.

C-252 de 2001. 
C-486 de 1993.

C-836 de 2001.

C 1040 de 2005.

T-292 de 2006.

C 588 de 2009.

C 141 de 2010.

C-816 de 2011.

C 249 de 2012.

C 1056 de 2012.

\section{NORMATIVA}

Constitución Política de Colombia.

Ley 163 de 1896.

Ley 61 de 1886.

Ley 57 de 1887.

Ley 153 de 1887.

Ley 105 de 1890. 